\title{
A DOCÊNCIA COMO MATRIZ DE EXPERIÊNCIA E A CONSTITUIÇÃO DO/A PROFESSOR/A EM UMA SOCIEDADE INCLUSIVA
}

\author{
TEACHING AS A MATRIX OF EXPERIENCE AND TEACHER'S CONSTITUTION IN AN INCLUSIVE SOCIETY
}

DOCENCIA COMO MATRIZ DE EXPERIENCIA Y LA CONSTITUCIÓN DE EL/LA PROFESOR/RA EN UNA SOCIEDAD INCLUSIVA

\author{
OLIVEIRA, Sandra1 \\ WESCHENFELDER, Viviane Inês²
}

\begin{abstract}
RESUMO
Ao compreender a docência como uma matriz de experiência, esquema teórico criado por Michel Foucault, este artigo problematiza os modos de constituir-se professor/a em uma sociedade inclusiva. A partir das investigações desenvolvidas no interior de dois grupos de pesquisa, o argumento central é de que os três eixos que compõem a matriz de experiência (saberpoder-ética) são importantes para compreendermos a constituição da docência contemporânea e os processos de subjetivação do sujeito professor. A análise de narrativas de estudantes de Pedagogia evidencia a constituição de uma docência virtuosa, colocada em operação através das técnicas do comprometimento, da tática e da intervenção. Essa docência é, em grande parte, mobilizada pelo imperativo da inclusão, indicando novos modos de tornar-se professor/a na Contemporaneidade.
\end{abstract}

Palavras-chave: Docência. Matriz de experiência. Sociedade inclusiva. Formação de professores.

\section{ABSTRACT}

Understanding teaching as a matrix of experience, theoretical framework created by Michel Foucault, this paper problematizes the ways of constituting teacher in an inclusive society. From the investigations developed inside of two research groups, the main argument is that the three axes that compose the matrix of experience (knowledge-power-ethic) are important in order to understand the teaching constitution and the subjectivation processes of teacher subject. The analysis of Pedagogy students' narratives has shown the constitution of a virtuous teaching, placed in operation through the techniques of commitment, tactic, and intervention. This teaching is, in the most part, mobilized by the inclusion imperative, indicating new ways to become teacher in the Contemporary era.

Keywords: Teaching. Matrix of experience. Inclusive society. Teacher training

\section{RESUMEN}

Al comprender la docencia como una matriz de experiencia, esquema teórico desarrollado por Michel Foucault, este artículo problematiza los modos de constituirse profesor/ra en una sociedad inclusiva. A partir de las investigaciones desarrolladas en el interior de dos grupos de investigación, el argumento central es que los tres ejes que componen la matriz de la experiencia (saber-poder-ética) son importantes para comprender la constitución de la docencia contemporánea y los procesos de subjetivación del sujeto profesor. El análisis de narrativas de estudiantes de pedagogía evidencia la constitución de una docencia virtuosa, colocada en operación a través de las técnicas de comprometimiento, de la táctica y de la intervención. Esta docencia es, en gran parte, movilizada por el imperativo de la inclusión, indicando nuevos modos de convertirse en profesor/ra en la Contemporaneidad.

Palabras clave: Docencia. Matriz de experiencia. Sociedad inclusiva. Formación de profesores.

\footnotetext{
1 Universidade do Vale do Rio do Sinos - UNISINOS - São Leopoldo - Rio Grande do Sul - Brasil

2 Universidade do Vale do Rio do Sinos - UNISINOS - São Leopoldo - Rio Grande do Sul - Brasil
} 


\section{INTRODUÇÃO}

Se alguma coisa nos anima a educar é a possibilidade de que esse ato de educação, essa experiência em gestos, nos permita liberar-nos de certas verdades, de modo a deixarmos de ser o que somos, para ser outra coisa para além do que vimos sendo. (LARROSA; KOHAN, 2013, p. 5).

Como nos constituímos professores/as na Contemporaneidade? Quais modos de ser docente vêm sendo produzidos em uma sociedade que se propõe inclusiva? Sempre que somos conduzidos a pensar nos desafios da educação contemporânea, somos também conduzidos a olhar para as múltiplas implicações que tem constituído nossa profissão. Para além da precarização do sistema educacional, as mudanças sociais e culturais das últimas décadas têm feito com que muitos de nós deixemos de crer na potência da escola. Se a educação é um ato de amor pelo mundo, como nos mostrou Arendt (1961), pelo qual nos responsabilizamos enquanto professores/as, entendemos ser necessário retomar a questão nietzschiana de "como nos tornamos o que somos". Nesse viés, iniciamos este texto com as palavras de Larrosa e Kohan (2013), para quem tanto o gesto de escrever quanto de ensinar constituem experiências transformadoras. Através da escrita, compartilhar nossos pensamentos faz com que nos desloquemos por caminhos previamente impensados. Da mesma forma, ao ensinar o outro, ao transmitir a cultura deste mundo aos recém-chegados, também nos transformamos como professores/as.

Tornar-se professor/a na contemporaneidade é, sobretudo, assumir o desafio de incluir a todos e de responsabilizar-se pelas aprendizagens, considerando as diferenças de cada um. Desde os alunos com deficiência até as diferenças de raça/etnia, gênero e sexualidade, a sociedade inclusiva é a grande pauta educacional. Evidência disso são os inúmeros cursos de pós-graduação que se multiplicam no intuito de fabricar e de atender uma imensa demanda de professores/as que se sentem frágeis e incapazes de trabalhar com tantas diferenças em sala de aula, diferenças que exigem, cada vez mais, um olhar especializado. Sem colocar em questão a relevância dos espaços de formação continuada e da especialização dos saberes pedagógicos, nos propomos a problematizar alguns movimentos já apontados por Masschelein e Simons (2013). Esses autores mostram que a racionalidade contemporânea tem confrontado a escola e o/a professor/a, criando estratégias globais de profissionalização (operando através das competências) e de flexibilização, em uma tentativa de "domar" o/a professor/a e de restringi-lo/a a uma lógica da prestação de contas. O risco: "a pressão crescente da prestação de contas ameaça erradicar aquele amor e interesse pelo mundo (o amor pela causa como a causa) e pelos alunos". (MASSCHELEIN; SIMONS, 2013, p. 146). Como, então, podemos desenvolver e manter um equilíbrio entre as demandas educacionais contemporâneas e a responsabilidade de compartilharmos o mundo (e nosso amor pelo mundo)? 
Partindo destes questionamentos iniciais, construímos este texto, considerando nossa inserção na temática da docência e os processos de in/exclusão33, as investigações (OLIVEIRA, 2015; WESCHENFELDER, 2018) tomando como base o esquema teórico-analítico da matriz de experiência (FOUCAULT, 2013) e o exercício profissional, enquanto formadoras de professores. Nosso argumento central é de que os eixos dos saberes, do poder/governo e da ética são importantes para compreendermos a constituição da docência Contemporânea. Nesse caso, uma docência atravessada pelo imperativo da inclusão.

\title{
A DOCÊNCIA COMO MATRIZ DE EXPERIÊNCIA
}

\begin{abstract}
Docência significa o exercício da ação de um professor, de uma professora [...]. Só pode exercer a docência um professor em certa condição. Ele exerce a docência quando no contexto de um processo educativo intencional desenvolve o ensino, junto a um grupo de indivíduos que estão em posição de aprendentes - são alunos. Portanto, a docência pressupõe sujeitos em posições e funções diferenciadas de ensino e de aprendizagem. [...] A docência é uma condição exercida pelo professor, comprometido com o processo de ensino e com as possíveis aprendizagens promovidas a partir dele. (FABRIS; DAL'IGNA, 2017, p. 57).
\end{abstract}

Optamos por trazer o significado da docência descrito por Fabris e Dal'Igna (2017) porque consideramos importante definir os termos que nos são caros neste texto. Assim, o exercício docente significa a ação de um/a professor/a, uma ação que envolve intencionalidade pedagógica, com o intuito de ensinar e de produzir condições de aprendizagem a um grupo de indivíduos que assume a posição de alunos. Como profissionais que se constituem sujeitos em um terminado tempo, os/as professores/as desenvolvem sua docência com as marcas do período em que vivem, já que são profundamente afetados pelas demandas políticas, sociais, culturais, pelas condições materiais e pelas crenças de sua época.

Embora possamos identificar um conjunto de práticas e de concepções educacionais historicamente contínuas, há a compreensão geral de que não se pode ensinar os alunos de nossas escolas atuais do mesmo modo como se ensinava as gerações passadas. As transformações tecnológicas e a virada cultural - que passa a olhar mais atentamente para as diferenças e para os indivíduos até então excluídos do ambiente escolar - são elementos centrais dessa mudança nas configurações da escola e da docência. Para compreender os modos como nos constituímos professores/as em meio a esse cenário complexo, consideramos o esquema analítico da matriz de experiência um recurso produtivo.

Em seus estudos sobre a constituição do sujeito, Foucault apresenta o seguinte questionamento: De que maneira "constitui-se uma 'experiência' tal, que os indivíduos são levados a reconhecer-se como sujeitos"? (FOUCAULT, 2014, p. 8). A experiência, no sentido utilizado por

\footnotetext{
${ }^{3}$ Conceito cunhado no interior do Grupo de Estudo e Pesquisa em Inclusão (GEPI/CNPq/Unisinos). Para Lopes e Fabris (2013, p. 10), a noção de in/exclusão é, entre outros elementos, "uma maneira de dar visibilidade ao caráter subjetivo que está implicado nos processos de discriminação negativa e nos processos de degradação humana".
} 
Foucault, deve ser entendida como "a correlação, numa cultura, entre campos de saber, tipos de normatividade e formas de subjetividade". (FOUCAULT, 2014, p. 8). No curso O governo de si e dos outros (1982-1983), ministrado na cadeira de história dos sistemas de pensamento do Collège de France, Foucault descreve melhor seu esquema analítico. Na primeira hora da aula de 5 de janeiro de 1983, o filósofo retoma seu projeto de trabalho e posiciona-o no interior daquilo que chamou de focos ou matriz de experiência. Assim, ao questionar os modos pelos quais, em certa sociedade, constitui-se uma determinada experiência em que indivíduos passam a se reconhecer como sujeitos da loucura, da sexualidade, da doença ou da criminalidade, Foucault (2014) possibilitou a articulação dos três grandes empreendimentos que realizou ao longo de sua obra.

De acordo com Ortega (1999), é importante compreender o trabalho de Foucault a partir de três deslocamentos no interior do mesmo eixo, que resultaram na matriz de experiência. Em ordem cronológica, tivemos um primeiro deslocamento, no eixo do saber, que "vai da formação do conhecimento à análise das formas do dizer verdadeiro" (ORTEGA, 1999, p. 37); um segundo deslocamento, no eixo do poder, que "leva uma teoria geral do poder ou do domínio da história à análise dos procedimentos do pensamento governamental e de suas tecnologias" (ORTEGA, 1999, p. 37) e um terceiro deslocamento, no eixo do sujeito, que trata da relação do sujeito com a verdade e consigo através dos modos de subjetivação.

Para o autor, esses deslocamentos foram fundamentais para o avanço das pesquisas no âmbito da experiência foucaultiana. Sem os estudos da questão do governo, no âmbito do segundo eixo, não teria sido possível abordar as técnicas de si. "Somente depois de ter sido realizado o deslocamento Foucault pode passar do governo dos outros ao governo de si a fim de introduzir a temática da autoconstituição. A análise das práticas de governo permite relacionar as 'técnicas de poder' com as ‘técnicas de si’”. (ORTEGA, 1999, p. 37).

O esquema teórico-analítico desenvolvido por Michel Foucault (2013) é útil para compreendermos as três dimensões que constituem a docência e o sujeito professor, quais sejam: os saberes, a normatividade dos comportamentos e os modos de se constituir sujeito. Em algumas de nossas pesquisas, a matriz de experiência foucaultiana tem sido utilizada para pensar a inclusão (LOPES; MORGENSTERN, 2014), a docência (OLIVEIRA, 2015), a surdez (WITCHES, LOPES, 2015) e a negritude (WESCHENFELDER, 2018). Além disso, os trabalhos desenvolvidos no interior dos grupos de pesquisa GIPEDI 4 e GEPI são importantes para a reflexão aqui desenvolvida. Nessa reflexão, procuramos entender como a docência enquanto matriz de experiência é cada vez mais articulada com vistas a uma sociedade inclusiva. Está em jogo, nesse direcionamento, a governamentalidade neoliberal que coloca a inclusão como um imperativo, conduzindo todos os indivíduos a participarem, com mais ou menos intensidade, da racionalidade que governa tanto na dimensão individual quanto coletiva.

\footnotetext{
${ }^{4}$ Grupo Interinstitucional de Pesquisa em Docências, Pedagogias e Diferenças (GIPEDI), coordenado pela professora Dra. Elí Henn Fabris, sediado na Unisinos.
} 
A pesquisa realizada por uma de nós (OLIVEIRA, 2015) - e que sustenta boa parte das análises deste texto - parte da compreensão da docência como uma matriz de experiência, considerando a constituição do sujeito que se forja a partir das conexões entre saber, poder e ética. Oliveira (2015) analisou os processos envolvidos na constituição da docência (ou dos modos de ser docente) dos anos iniciais da educação básica brasileira, em um projeto desenvolvido em curso de Licenciatura em Pedagogia, na região sul do Brasil, vinculado ao primeiro programa brasileiro de iniciação à docência - o Programa Institucional de Bolsa de Iniciação à Docência (PIBID). Seu estudo mostrou que o programa brasileiro analisado "produz um modo de ser professor/a, uma docência virtuosa que conjuga os modos comprometida, tática e interventora". (2015, p. 8). A imagem a seguir apresenta o esquema desenvolvido por Oliveira (2015), permitindo a melhor compreensão da matriz:

Imagem 1 - Docência como matriz de experiência

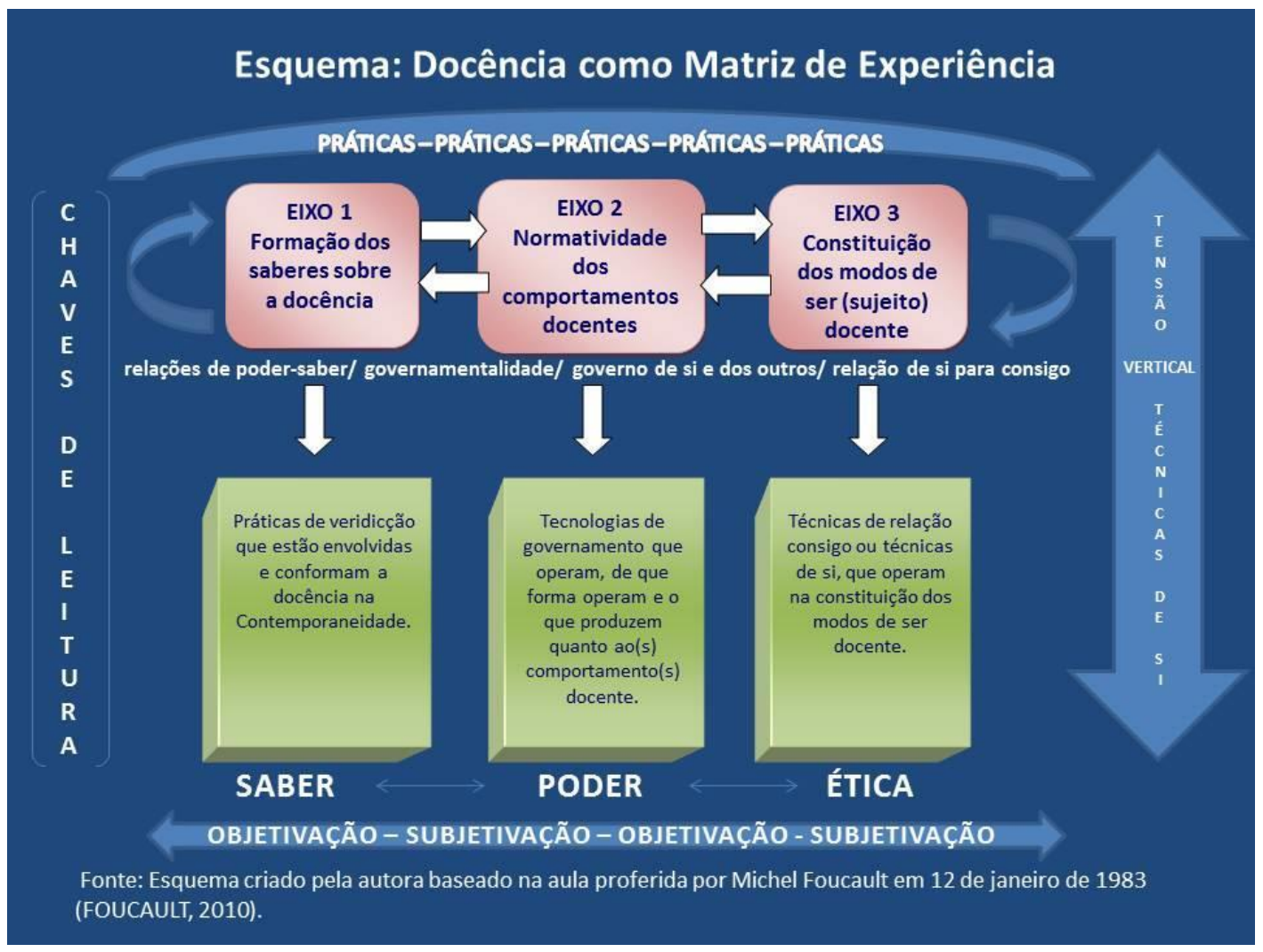

Fonte: Tese de Doutorado defendida por Oliveira (2015, p. 64).

Como podemos ver na imagem, a matriz de experiência se organiza a partir três focos, três dimensões que se articulam e se sobrepõem umas às outras. Formação dos saberes, normatividade dos comportamentos e constituição dos modos de ser formam o que Foucault chamou de uma história do pensamento. (FOUCAULT, 2013). Primeiro, "tratava-se de deslocar o eixo da história do conhecimento para a análise dos saberes, das práticas discursivas que organizam e constituem o elemento matricial desses saberes, e estudar as práticas discursivas como formas reguladas de 
veridição". (2013, p. 6). Segundo, "estudar as técnicas e procedimentos pelos quais se compreende conduzir a conduta dos outros, [...] passar da análise da norma à [análise] dos exercícios de poder; e passar da análise dos exercícios de poder aos procedimentos, digamos, de governamentalidade". (2013, p. 6). Terceiro, "analisar as diferentes formas pelas quais o indivíduo é levado a se constituir como sujeito, [...] analisar estas formas de subjetivação através das técnicas/tecnologias da relação consigo ou, vamos dizer, do que pode se chamar de pragmática de si”. $(2013$, p. 6).

A matriz de experiência aciona um modus operandi que produz determinadas formas de vida dos sujeitos que dela fazem parte. No caso da docência, as três dimensões (saber, poder/governo e ética) são interdependentes e produzem, ao mesmo tempo, relações de forças assujeitadoras e subjetivantes. Os saberes não apenas constituem a docência contemporânea, mas também funcionam como verdades que conduzem a conduta dos sujeitos professores e alunos, produzindo certos modos de ser professor/a. Para Fischer (2009), a docência pode ser pensada como um entrelugar, uma dobradiça que articula técnicas de dominação e técnicas de si. Isso quer dizer que não há total controle sobre a forma como os saberes atuam enquanto verdades sobre nossa constituição, mas não somos sujeitos passivos. Ao entrar em contato com essas verdades, relacionamo-nos com os outros e com nós mesmos, produzindo ao mesmo tempo movimentos de sujeição e de subjetivação. É por essa razão que Fischer (2009, p. 94) entende a docência como

Um lugar privilegiado de experimentação, de transformação de si, de exercício genealógico lugar de indagação sobre de que modo nós fizemos desta e não daquela forma; de que modo temos aceitado isto e não aquilo; de que modo temos recusado ser isto ou aquilo, no caso, como docentes.

Assim, pensar a docência a partir de uma matriz de experiência é uma proposição que está amparada em uma perspectiva hipercrítica (VEIGA-NETO, 1995), ou no exercício constante de uma crítica radical (LOPES; FABRIS, 2013). Esta perspectiva implica em "desterritorializar, desfamiliarizar, levar ao estranhamento" (VEIGA-NETO, 2007, p. 25) aqueles aspectos que estão aparentemente naturalizados em nossas formações discursivas. Para Foucault (2006, s/p), "uma crítica não consiste em dizer que as coisas não estão bem como estão. Ela consiste em ver sobre que tipos de evidências, de familiaridades, de modos de pensamento adquiridos e não refletidos repousam as práticas que se aceitam". Diferente de outras perspectivas, na crítica foucaultiana não "se trata de uma crítica transcendental, seja ela ancorada num outro mundo, seja ela enganchada no céu; mas se trata, sim, de uma crítica que é arqueológica e genealógica". (VEIGA-NETO, 2007, p. 24). O radical está relacionado ao fundamento, à raiz de determinadas práticas que, juntas, articulam a teia discursiva que dá corpus à matriz de experiência. Para Lopes e Fabris (2013, p. 13, grifo das autoras), "por crítica radical, portanto, entendemos a busca, na raiz dos acontecimentos, as distintas condições de possibilidade daquilo que o determina".

Ao analisar as verdades que concorrem na condução da conduta docente e instituem seus modos de ser e agir, é possível perceber uma estreita ligação com as formas de governamento político neoliberal. A postura colaborativa e investigativa das estudantes de licenciatura, identificadas no 
decorrer das análises (OLIVEIRA, 2015), nos mostra os modos de ser da docência virtuosa, uma docência produzida como tática de enfrentamento para a complexidade da educação básica brasileira. Uma docência constituída na relação universidade e escola como peça estratégica para a construção de uma sociedade inclusiva, como mostramos nas seções que seguem.

\section{A DOCÊNCIA NA E PARA A SOCIEDADE INCLUSIVA: A CONDUÇÃO DE TODOS E DE CADA UM}

Embora Foucault não tenha se ocupado diretamente dos problemas da Educação, seus estudos nos oferecem possibilidades para pensar a escola contemporânea. O filósofo nos convida a problematizar as práticas deste tempo para, quem sabe, conduzirmo-nos de forma mais livre no mundo, tornando-o um lugar melhor para se viver ou ainda, para que no exercício de pensar de outro modo, possamos encontrar pensamentos ainda não experimentados.

Exercitar a crítica radical das lógicas que enquadram nossas maneiras de pensar e de ser é uma prática de liberdade, já que a problematização é uma chave para "abrir a porta". Nas palavras de Foucault (2000, p. 320), “uma possibilidade aberta 'permanentemente' [que] permite ao indivíduo modificar-se ao seu gosto". Problematizar uma racionalidade significa rachá-la, dessecá-la, desmantelá-la em micropartículas (microfísica), buscando destrinchá-las em seu caráter discursivo e sistemático (saber-poder-ética). Para isso, é preciso olhá-las de cima, desde sua manifestação, desde as práticas.

Nesse sentido, importa atentarmos às práticas que têm sido utilizadas para que os sujeitos se dobrem a determinadas verdades no campo da formação inicial e, mais especificamente, nas práticas de iniciação à docência. Ao mesmo tempo, importa também identificar quais verdades têm constituído a docência para compreender como nos tornamos professores/as. Para Meyer (2013, p. 11), verdades "são campos de disputa e de exercício de poder, para além de campos de produção de saber e de legitimação de verdades. É nos regimes de verdade que se constitui o que é dizível e, portanto, também pensável e compartilhável, em cada época, em cada lugar". Na Contemporaneidade, a preponderância dos discursos voltados à aprendizagem e sua instauração no âmbito do direito implicou diretamente nas mudanças observadas na escola e nos modos de ser professor/a no Brasil contemporâneo. Por essa razão, vale perguntarmo-nos: quais os efeitos da forte ênfase dada à aprendizagem para a constituição do/a professor/a?

Como nos mostrou Noguera-Ramírez (2011), a noção de aprendizagem (/earning) foi o conceito pedagógico preponderante do século $X X$ e continua sendo neste início de século $X X I$. $A$ expansão da aprendizagem tem íntima relação com o desenvolvimento e o aprimoramento do campo psicológico, colocada em operação especialmente através da necessidade e do interesse de cada indivíduo. Nessa nova ênfase, a escola não é mais o único espaço educativo e talvez nem seja o mais importante: o indivíduo torna-se um aprendiz permanente, sendo ele cada vez mais responsabilizado pelas competências que desenvolve. 
Os processos de regulação são cada vez mais internalizados, através da contínua produção de subjetividades dos sujeitos que devem tornar-se autônomos e autorreflexivos. Deste modo, a conduta dos indivíduos continua sendo regulada, mas por meio das liberdades. As novas formas de regulação fazem parte do que chamamos de governamentalidade neoliberal. A governamentalidade foi definida por Foucault (2008, p. 143) como o conjunto de técnicas que "tem por alvo principal a população, por principal forma de saber a economia política e por instrumento técnico essencial os dispositivos de segurança". Em nossas pesquisas, ela vem sendo compreendida como uma grade de inteligibilidade, como lentes que nos permitem olhar para as relações de governamento que constituem os sujeitos e as suas práticas. Nas palavras de Marín-Díaz (2015, p. 20), "nesse jogo de desaprender e aprender novas formas de agir, o indivíduo se transforma em capital humano - competente e aprendiz permanente - forma necessária para o desenvolvimento do governamento neoliberal contemporâneo".

Para compreender como esse movimento reverbera na educação escolar, vale a pena olharmos para os argumentos de Biesta (2013). O autor aponta que "a linguagem da educação tem sido em grande parte substituída por uma linguagem da aprendizagem". (BIESTA, 2013, p. 30, grifos do autor). Essa substituição não é problemática em si mesma, mas mostra que, com ela, algo importante da dimensão da escola e da docência corre o risco de se perder. A ênfase na aprendizagem favorece com que a educação seja pensada "como uma transação econômica, como um processo de satisfazer a necessidade do aprendente". (BIESTA, 2013, p. 41). Deste modo, "as questões sobre o conteúdo e o objetivo da educação não se tornam só totalmente individualizadas. Numa escala mais ampla, podem se tornar sujeitas às forças do mercado". (BIESTA, 2013, p. 42, grifo do autor).

Sem entrar nesta questão de como as forças mercadológicas têm afetado as demandas da formação de professores, é interessante perceber como a ideia de intervenção pedagógica vem sendo usada, incorporada à linguagem de aprendizagem, para dar conta dos direitos de aprendizagem, colocando o/a professor/a a serviço do Estado. Com isso, não estamos dizendo que a ideia de intervenção é ruim ou boa em si mesma; apenas alertando que é preciso pensar para quê e para quem ela está servindo. A substituição de alguns termos educacionais, que em um primeiro momento nos parece "longe de qualquer suspeita", merece maior cautela. Cabe a nós exercitarmos o estranhamento dos discursos que atravessam esses termos que, em consequência de sua força de "inovação", acabam se tornando verdades.

A pesquisa realizada por Oliveira (2015) tornou possível compreender que a docência contemporânea vem sendo produzida a partir de práticas centradas em diagnósticos e intervenções para a inclusão do sujeito e maximização de sua performance. A linguagem de aprendizagem institui um campo composto por técnicas saber, poder e governo postas a operar, tecnologizando a conduta não somente do aluno dos anos iniciais, mas também do futuro/a professor/a. A autora identificou três aspectos determinantes das práticas de iniciação à docência; são eles: a) a preponderância dos discursos voltados à aprendizagem e sua instauração no âmbito do direito; b) a ênfase no saber-fazer ligada a ideia de competência, eficácia e produtividade e; c) a intervenção pedagógica com foco no desenvolvimento da performance e melhora do desempenho do aluno. (OLIVEIRA, 2015). Essa trama 
discursiva participa dos processos de subjetivação docente, produzindo uma professora ${ }^{5}$ comprometida, tática e interventora que atua com responsabilidade social. Assim, essa profissional "engole o Estado" e, ao mesmo tempo, torna-se indispensável à sustentação de uma sociedade inclusiva.

Por meio do estudo, do olhar individual, da observação, da investigação por parte da docência, das características principalmente psicológicas, comportamentais e sociais dos alunos também chamados de "aluno de inclusão", a professora em formação age como uma terapeuta nas intervenções da aprendizagem. Conforme Ramos do Ó e Carvalho (2009, p. 18), esse "propósito de ajustar as práticas educativas à diversidade de casos particulares - ou o ensino por medida transformar-se-ia, assim, na máxima pedagógica por excelência”. Esta nova forma de intervenção, muito mais refinada, possibilitou que as condutas dos escolares passassem a ser conduzidas desde uma articulação sutil, mas não menos eficaz, entre o governamento ético e governamento político da criança, "através de uma prática cada vez mais definida como da autonomia funcional e da liberdade". (RAMOS DO Ó; CARVALHO, 2009, p. 18, grifos do autor). É por essa razão que o grande desafio que se coloca para a docência, hoje, é a individualização do ensino.

Compreender a inclusão "como um conjunto de práticas que subjetivam os indivíduos de forma que eles passem a olhar para si e para o outro, sem necessariamente ter como referência fronteiras que delimitam o lugar do normal e do anormal, do incluído e do excluído" (LOPES, 2009, p. 154) contribui para o alargamento da compreensão de quem são os sujeitos a incluir na escola. Não se trata apenas do atendimento especializado aos alunos com deficiência, a customização curricular (SILVA, 2017) torna-se um dispositivo importante e necessário para todos os estudantes, pois cada aluno é um aluno. Obviamente, questões que atravessam raça/etnia, gênero e sexualidade e dificuldades de aprendizagem estão amplamente contempladas nas políticas educacionais para a educação inclusiva. Talvez, vale a pena refletirmos o quanto estas demandas da educação pela diferença não servem também como um propósito para garantir que os professores necessitem, com cada vez mais eficiência, governar ao mesmo tempo todos e cada um.

\section{DOCÊNCIA VIRTUOSA: UM FAZER COMPROMETIDO COM AS DIFERENÇAS}

Tendo em vista a discussão desenvolvida até aqui, defendemos a importância de problematizar as verdades constituidoras da matriz de experiência. Essas verdades dão sustentação às práticas de iniciação à docência das quais participam as estudantes de licenciatura, bem como seu uso na relação consigo e com os outros no processo de formação. Trata-se de problematizar a naturalização de atributos como "comprometimento" e "responsabilização", tão caros à educação contemporânea, no

\footnotetext{
${ }^{5}$ Adotamos o uso professor/a para referir-nos a homens e mulheres envolvidos com a profissão docente. Essa opção pela flexão de gênero é política e decorre de nossa aproximação com o campo dos Estudos Feministas. Além disso, como as alunas de Pedagogia são maior número, utilizaremos os termos no feminino sempre que nos referirmos ao escopo do curso de Pedagogia da universidade. Contudo, a flexão de gênero não ocorre em todo o texto, em função de sua fluidez.
} 
âmbito das racionalidades que sustentam essas verdades. Talvez, os sujeitos pesquisados estão indicando outras subjetividades docentes que vêm sendo constituídas na Contemporaneidade, para as quais precisamos atentar.

Oliveira (2015) identificou a produção de uma docência virtuosa que conjuga os modos de ser comprometida, tática e interventora. Mostrou, também, que a subjetividade docente é produzida por uma matriz de experiência colocada em operação nas práticas de iniciação à docência do Pibid, expressas e movimentadas por essa docência virtuosa.

O conceito de docência virtuosa expressa a junção de dois outros conceitos, qual sejam, virtual e virtuoso, ambos com o mesmo radical. Virtu é a capacidade de agir corretamente diante de uma situação, o radical virtus significa força, potência. (BLACKBURN, 1997). O termo virtual expressa a ideia de algo existente em potência, que não pode ser visto tal qual, mas como algo ou coisa que está por vir a ser. O virtual, nesse sentido, não pode ser entendido como o oposto ao real. O virtual carrega uma potência do vir a ser, enquanto o real já é, o virtual seria a existência em potência do que vem a ser. Do latim medieval virtualis e do latim clássico virtus, significam força de espírito, ânimo, amor e prática do bem, que tem virtudes. O virtuoso é um técnico bem formado e competente, um performer, aquele que apresenta bom desempenho. A pessoa virtuosa é aquela que produz efeitos e tem predisposição firme para o bem, apresenta eficácia, que tem força, que tem capacidades. As virtudes, no entanto, são "invisíveis", somente identificáveis no âmbito das ações dos indivíduos, no âmbito da prática, no conjunto perceptível de suas ações.

Ao desenvolver esse argumento, apresentamos algumas verdades construídas nas relações que sustentam um trabalho ético, com efeitos na produção da subjetividade docente, que tem como alvo um vir a ser virtuoso. Dessa forma, institui-se uma verdade ética que pode fundamentar o sujeito em seu processo de tornar-se professor/a, modificando seus modos de ser e de agir, pois, para tornarse professor/a na Contemporaneidade, é preciso fazer parte de uma coletividade específica: a docência virtuosa para uma sociedade inclusiva.

Embora as licenciandas estejam banhadas por discursos oriundos da teoria crítica, das teorias psi, especialmente da Escola Ativa, que imperam no curso de Pedagogia do projeto analisado, tudo isso se põe a serviço de uma racionalidade neoliberal. As licenciandas não conseguem fugir desse regime de verdades que atravessa o Programa e a escola de educação básica, constituindo as práticas de iniciação à docência e as próprias participantes. Nesse caso, a docência virtuosa é providencial, visto que a pessoa virtuosa é aquela que produz efeitos e tem predisposição firme para o bem, apresenta eficácia, que tem força, que tem capacidades para fazer bem feito.

Os modos de ser da docência para uma sociedade inclusiva, identificados no exercício analítico - comprometida, tática e interventora -, colocados em ação ou acionados a partir de uma matriz de experiência, funcionam como modus operandi, como uma maneira de agir, de executar, de viver a docência, conforme determinadas prescrições e procedimentos, como se fossem códigos de conduta profissional. Embora apresentados de forma separada, esses modos de ser não se mostram de 
maneira dissociada; eles se atravessam e se complementam, implicando na tomada de decisão para o agir da docência virtuosa.

É possível inferir que as práticas de iniciação à docência do curso de Pedagogia analisado vêm instituindo uma verdade ética na qual pode fundamentar-se o sujeito em seu processo de tornar-se professor/a: uma ética do saber-fazer, do fazer bem feito. Para tornar-se professor/a no programa analisado, a licencianda necessita ser tática. Segundo o Dicionário Houaiss (2013), tático é aquele que está treinado, que possui um treinamento intensivo e está preparado para desenvolver técnicas operacionais. O/a professor/a tático/a é aquele/a dotado/a de condições técnicas para observar, planejar e fazer o que tem que ser feito para a aprendizagem de seus alunos. Este/a professor/a diz que a reflexão faz parte do seu agir, bem como ressalta ter uma postura investigativa. É preciso estar atento/a a todos e a cada um de forma minuciosa, detalhista, o que somente pode fazer um/a professor/a investigador/a.

Para compor esses argumentos, trazemos para esse espaço mais algumas questões discutidas por Biesta (2012). Em seus estudos ${ }^{6}$, o autor vem propondo uma formação de professores com base no virtuosismo, ou ainda, na capacidade de tomar decisões educacionais sábias que está para além do desenvolvimento de competências. Biesta (2013) sugere uma formação centrada em modelos de professores considerados virtuosos e afirma que estudar o virtuosismo de professores identificados com certo nível de virtuosidade, seja nas escolas, na literatura, no cinema etc., seria uma prática importante a ser incorporada na formação de professores. Segundo ele, "para desenvolver o virtuosismo é preciso estar próximo desse professor virtuoso, dessa professora que você aspira ser". (BIESTA, 2012, p.18, tradução nossa).

Entre a proposta de Biesta e o que ocorre no programa analisado, há uma diferença considerável. Os pibidianos ${ }^{7}$ não estão restritos a conviver apenas com os professores "considerados virtuosos", nem recebem como modelo um guia de "boas práticas", tampouco apregoadas na formação continuada de professores oriunda do MEC (Ministério da Educação) e em documentos publicados por organizações internacionais, como UNESCO (Organização das Nações Unidas para a Educação, a Ciência e a Cultura) e OCDE (Organização para a Cooperação e Desenvolvimento Econômico), mas são incentivados a identificar práticas relevantes, a partir das quais devem refletir. Ao apresentar essas práticas nas reuniões ritualizadas, junto com o grupo de pibidianos, criam-se momentos para os licenciandos conhecerem outras formas de condução pedagógica, para pensarem juntos sobre o que viram.

Esse "pensar junto" que ocorre nas reuniões é proposto a partir das problematizações das práticas observadas ou vivenciadas pelos pibidianos. As práticas destacadas em seus Diários de Campo, geralmente chamadas por eles de práticas relevantes ou significativas, independem de serem

\footnotetext{
${ }^{6}$ Trata-se aqui, especificamente, do texto publicado com base na fala do autor na abertura da conferência 2020 The Future of Teacher Education, ocorrida em Viena/Áustria, nas datas de 3 e 4 de Março de 2011.

${ }^{7}$ Adotamos o uso pibidiano, geralmente no masculino, por nos referir ao sujeito pibidiano e, por ser esta a forma recorrente encontrada no âmbito do Programa de Iniciação à Docência. Mesmo entre as alunas da licenciatura em Pedagogia, prevalece a expressão "Sou Pibidiano!".
} 
"práticas de sucesso", são práticas que foram destacadas por algum motivo que chamou a atenção dos pibidianos, práticas que os levaram a uma reflexão e possível problematização. Tudo aquilo que ele viu e o afetou, causando-lhe uma tensão tal que Ihe motiva a discutir, refletir, problematizar sobre, é considerado produtivo.

Um dos enunciados mais potentes percebido nas respostas e nos relatos dos sujeitos envolvidos é a mobilização das licenciaturas e das escolas participantes do Pibid para a discussão e a problematização da formação docente. Essa mobilização pode indicar o investimento em uma formação menos pragmática. Conforme Dal'Igna e Fabris,

\footnotetext{
Tendo como ponto de partida a problematização, os estudantes de licenciatura/pibidianos aprendem a movimentar-se empreendendo esforços para duvidar do já sabido. Isso exige um exame da própria condição como sujeito imerso em determinados problemas, os quais ele mesmo pode des-construir. (2015, p. 86, grifos das autoras).
}

A postura colaborativa e a postura investigativa, identificadas no decorrer das análises, mostram-nos os modos de ser da docência virtuosa, um/a professor/a produzida como tática de enfrentamento para a complexidade da educação básica brasileira a partir do imperativo da inclusão. Um/a professor/a constituído/a na relação universidade e escola como peça estratégica para a construção e a manutenção de uma sociedade inclusiva.

Desde o século XIX, diferentes métodos foram criados, inspirados nas teorias interacionistas do desenvolvimento intelectual, entre eles, o método freiriano para alfabetização de adultos. Esses métodos, articulados a partir do professor como um interventor pedagógico, vêm sendo amplamente utilizados nas propostas e nos programas de formação docente vinculados às políticas de formação do MEC e anunciados como metodologias eficazes na melhoria do desempenho de alunos no Índice de Desenvolvimento da Educação Básica - IDEB. Para tudo isso, o professor necessita estar munido de todo um arcabouço derivado de saberes pedagógicos, específicos da docência, e saberes psi oriundos da psicologia e psicopedagogia, os quais the permitirão trabalhar com "evidências" sobre as necessidades e a "real situação" do aluno. É deste modo que o professor passa a atuar como um interventor na condução da vida dos estudantes, tomando cada aluno como um caso individual a ser investido e maximizando a sua performance para que possam aprender sempre mais. Quanto mais preparado está o professor para diagnosticar e intervir, menos ele precisará da ajuda de outros profissionais para corrigir problemas que possam surgir no percurso da aprendizagem de seus alunos, tornando o processo muito mais econômico. Noguera-Ramirez (2011, p. 242) afirma que "o interesse garante uma economia da ação, uma economia das forças, e a aprendizagem é a ação mais eficiente que um organismo pode conseguir enquanto significa uma adaptação, porém, crescimento, desenvolvimento".

O conceito de intervenção pedagógica está relacionado à teoria histórico-cultural, difundida a partir dos estudos de Vygotsky (1988). Em suas investigações psicoeducativas, Vygotsky defendeu a importância do trabalho do professor, em face de uma intervenção pedagógica eficaz para o avanço das aprendizagens dos escolares e para o seu desenvolvimento psicossocial. O olhar diferenciado e 
comprometido possibilita outras formas de intervenção: uma docência comprometida com as diferenças e a singularidade de cada aluno. As experiências das bolsistas do Pibid, licenciandas em Pedagogia, nos desafiam a pensar em outras possibilidades de constituição de um/a professor/a que exerce sua profissão com responsabilidade ética e comprometimento com as diferenças.

\section{REFERÊNCIAS}

1. ARENDT, Hannah. A crise da educação. Publicado originalmente em 1961. Disponível em: http://www.gestaoescolar.diaadia.pr.gov.br/arquivos/File/otp/hanna_arendt_crise_educacao.pdf. Acesso em: 25 fev. 2018.

2. BIESTA, Gert. The future of teacher education: Evidence, competence or wisdom? Research on Steiner Education, v. 3, n. 1, p. 8-21, jul. 2012.

3. BIESTA, Gert. Para além da aprendizagem: educação democrática para um futuro humano. Tradução de Rosaura Eichenberg. Belo Horizonte: Autêntica, 2013.

4. BLACKBURN, Simon. Dicionário Oxford de Filosofia. Rio de Janeiro: Jorge Zahar, 1997.

5. DAL'IGNA, Maria Cláudia; FABRIS, Elí Henn. Constituição de um ethos de formação no Pibid/Unisinos: processos de subjetivação na iniciação à docência. Educação Unisinos, v. 19, n. 1, p. 77-87, jan./abr. 2015.

6. FABRIS, Elí T. Henn; DAL'IGNA, Maria Cláudia. Nenhuma escola está imune às ondas de violência e conservadorismo. IHU On-line, n. 516, ano XVII, p. 56-60, dez. 2017.

7. FISCHER, Rosa Maria B. Docência, cinema e televisão: questões sobre formação ética e estética. Revista Brasileira de Educação, v. 14, n. 40, p. 93-102, jan./abr. 2009.

8. FOUCAULT, Michel. Ditos e escritos II: Arqueologia das ciências e história dos sistemas de pensamento. Rio de Janeiro: Forense Universitária, 2000.

9. FOUCAULT, Michel. Est-il donc important de penser?. In: FOUCAULT, Michel. Dits et écrits IV (1980-1988). Paris: Gallimard, 2006. p. 178-182.

10. FOUCAULT, Michel. Segurança, Território, População. Curso dado no Collége de France (19771978). Tradução de Eduardo Brandão. São Paulo: Martins Fontes, 2008. 
11. FOUCAULT, Michel. O governo de si e dos outros: Curso no Collège de France (1982-1983). Tradução de Eduardo Brandão. São Paulo: Martins Fontes, 2013.

12. FOUCAULT, Michel. História da Sexualidade 2: o uso dos prazeres. Tradução de Maria Thereza da Costa Albuquerque. São Paulo: Paz \& Terra, 2014.

13. HOUAISS. Dicionário Houaiss Eletrônico da Língua Portuguesa- CD-ROM. Rio de Janeiro: Objetiva, 2013.

14. LARROSA, Jorge; KOHAN, Walter. Apresentação da coleção. In: BIESTA, Gert. Para além da aprendizagem: educação democrática para um futuro humano. Tradução de Rosaura Eichenberg. Belo Horizonte: Autêntica, 2013. p. 5-6. (Coleção Educação: Experiência e Sentido).

15. LOPES, Maura Corcini. Políticas de Inclusão e Governamentalidade. Educação \& Realidade, v.34, n.2, p. 153-169, mai./ago. 2009.

16. LOPES, Maura Corcini; MORGENSTERN, Juliane Marschall. Inclusão como matriz de experiência. Pro-Posições, v. 25, n. 2 (74), p. 177-193, maio/ago. 2014.

17. LOPES, Maura C.; FABRIS, Elí T. H. Inclusão \& Educação. Belo Horizonte: Autêntica, 2013.

18. MARÍN-DÍAZ, Dora L. Autoajuda, educação e práticas de si: genealogia de uma antropotécnica. Belo Horizonte: Autêntica, 2015.

19. MASSCHELEIN, Jan; SIMONS, Maarten. Em defesa da escola: uma questão pública. Tradução de Cristina Antunes. Belo Horizonte: Autêntica, 2013. (Coleção Educação: Experiência e Sentido).

20. MEYER, Dagmar. Postura investigativa no ensino superior. Conferência proferida em julho de 2013 na Capacitação para Professores e Tutores 2013/2: Postura Investigativa no Ensino Superior na Unisinos. São Leopoldo, 2013.

21. NOGUERA-RAMÍREZ, Carlos E. Pedagogia e governamentalidade ou Da Modernidade como uma sociedade educativa. Belo Horizonte: Autêntica, 2011.

22. OLIVEIRA, Sandra de. Sou PIBID!: tornar-se professor/a: matriz de experiência e processos de subjetivação na iniciação à docência. 254 f. Tese (Doutorado em Educação) - Programa de PósGraduação em Educação, Universidade do Vale do Rio dos Sinos (UNISINOS), São Leopoldo, 2015. 
OLIVEIRA, Sandra de; WESCHENFELDER, Viviane I. Práticas in/exclusivas e os modos de ser professor/a na Contemporaneidade. In: LOUREIRO, Carine B; KLEIN, Rejane S. (Orgs.) Inclusão e aprendizagem: contribuições para pensar as práticas pedagógicas. Curitiba: Apris, 2017. p. 77-100.

24. ORTEGA, Francisco. Amizade e estética da existência em Michel Foucault. Rio de Janeiro: Graal, 1999.

25. RAMOS DO Ó, Jorge; CARVALHO, Luis Miguel. Emergência e Circulação do Conhecimento Psicopedagógico Moderno (1880-1960):Estudos Comparados Portugal-Brasil. Educa, Unidade de I\&D de Ciências da Educação, 2009.

26. SILVA, Roberto R. D. Emocionalização, algoritmização e personalização dos itinerários formativos: como operam os dispositivos de customização curricular? Currículo sem Fronteiras, v. 17, n. 3, p. 699-717, set./dez. 2017.

27. VEIGA-NETO, Alfredo. Michel Foucault e Educação: há algo de novo sob o sol? In: VEIGANETO, Alfredo (org). Crítica Pós-Estruturalista e Educação. Porto Alegre: Sulina, 1995.

28. VEIGA-NETO, Alfredo. Foucault \& a Educação. 2. Ed. Belo Horizonte: Autêntica, 2007.

29. WITCHS, Pedro Henrique; LOPES, Maura Corcini. Surdez como matriz de experiência. Revista Espaço (INES), Rio de Janeiro, n. 43, p. 32-48, jan./jun. 2015.

30. WESCHENFELDER, Viviane Inês. Modos de (re)existir, de (res)sentir: mulheres negras e relações raciais na educação contemporânea. 2018. 298f. Tese (Doutorado em Educação) - Programa de Pós-Graduação em Educação, Universidade do Vale do Rio dos Sinos - UNISINOS, São Leopoldo, 2018.

31. VYGOTSKY, Lev; LURIA, A. R.; LEONTIEV, A. N. Linguagem, Desenvolvimento e Aprendizagem. São Paulo, Ícone: Edusp, 1988.

\section{Sandra de Oliveira}

Técnica em Educação. Docente da Especialização em Educação Inclusiva.

\section{Viviane Inês Weschenfelder}

Doutoranda do PPG em Educação da Unisinos. 


\section{Como citar este documento:}

OLIVEIRA, Sandra de; WESCHENFELDER, Viviane Inês. A docência como matriz de experiência e a constituição do/a professor/a em uma sociedade inclusiva. Reflexão e Ação, Santa Cruz do Sul, v. 26, n. $3, \quad$ nov. 2018. ISSN 1982-9949. Disponível em: $<$ https://online.unisc.br/seer/index.php/reflex/article/view/11754>. Acesso em: 19 nov. 2018. doi:https://doi.org/10.17058/rea.v26i3.11754. 